\title{
Comparison of the Characteristics and Outcomes of Patients Undergoing Concurrent CABG with MVR
}

Md. Alauddin ${ }^{1 *}$, Md. Zanzibul Tareq ${ }^{2}$, Abu Jafar Md. Tareq Morshed ${ }^{3}$, Md. Mohiuddin Aslam ${ }^{4}$, Dharmendra Joshi $^{5}$, NurA-Musabber ${ }^{6}$, Hridita Nawrin ${ }^{7}$, Nazrana Martuza ${ }^{8}$, Nahedul Morshed $^{9}$

${ }^{1}$ Medical officer, Department of Cardiac Surgery, Bangabandhu Sheikh Mujib Medical University, Dhaka, Bangladesh

${ }^{2}$ Assistant Registrar, Cardiac Surgery, National Institute of Cardiovascular Diseases (NICVD), Dhaka, Bangladesh

${ }^{3}$ Assistant Registrar, Cardiac Surgery, National Institute of Cardiovascular Diseases (NICVD), Dhaka, Bangladesh

${ }^{4}$ Assistant Professor, Department of Orthopedic Surgery, SZMCH, Bogura, Bangladesh

${ }^{5}$ Resident, Department of Cardiac Surgery, Bangabandhu Sheikh Mujib Medical University, Dhaka, Bangladesh

${ }^{6}$ Medical Officer, Department of Endocrinology, MMCH, Mymensingh, Bangladesh

${ }^{7}$ Medical Officer, Covid19 Telehealth Service, DGHS, Bangladesh

${ }^{8}$ Assistant Professor, Biochemistry, Ashiyan Medical College, Dhaka, Bangladesh

${ }^{9}$ Resident Medical Officer, NHF\&RI, Dhaka, Bangladesh

DOI: $10.36347 /$ sjams.2020.v08i12.019

| Received: 25.11 .2020 | Accepted: 03.12.2020 | Published: 14.12.2020

*Corresponding author: Md. Alauddin

Abstract

Original Research Article

Background: Concomitant CABG patients in undergoing mitral valve replacement (MVR) has been shown to be an important risk factor for hospital mortality. Patients who have each mitral valve dysfunction and atherosclerotic coronary artery disease (CAD) kind a heterogeneous cluster in terms of origin of the control disease, extent of coronary atherosclerosis, left ventricular function, and hemodynamic standing at operation. Objective: To assess preoperative characteristics, postoperative complications, in-hospital mortality rate, and length of stay in hospital for patients undergoing concurrent CABG with MVR. Materials and Methods: Study were preoperative and postoperative clinical data from 175 patients undergoing concurrent CABG with MVR operation at Department of Cardiac Surgery, Bangabandhu Sheikh Mujib Medical University, Dhaka, Bangladesh from Jun 2018 to July 2020 were collected and entered into a database. Information was obtained by clinical and case note review as well as detailed questionnaires to physicians and patients. Results: This study were 175 concurrent CABG with MVR operations performed on patients. The mean age of patients was $57.95 \pm 10.54$ years and $5.7 \%$ were under 40 years. Male/female ratio was 1.05 (male $51.4 \%$, female $48.6 \%$ ). The mean ejection fraction was $48.15 \pm 10.14$ and $\mathrm{BMI} \geq 30$ was $18.3 \%$. Among studied patients, $18.3 \%$ and $2.9 \%$ underwent aortic and tricuspid valve replacement, respectively. In-hospital mortality was $6.9 \%$ and $96.0 \%$ of patients were hospitalized $\geq 14$ days. History of congestive heart failure $(P=0.027)$ and postoperative brain stroke $(P=0.004)$ were independent predictors for in-hospital mortality. Conclusion: In conclusion, based on the outcome of this research, among postoperative characteristics, re-intubation and congestive heart failure were associated with in-hospital mortality after concurrent CABG with MVR operation. Therefore, exact considering and control of these characteristics before and after CABG and MVR are necessary.

Keywords: Coronary Artery Bypass Grafting, Mitral Valve Replacement, Outcome, In-Hospital Mortality.

Copyright $\odot 2020$ The Author(s): This is an open-access article distributed under the terms of the Creative Commons Attribution 4.0 International License (CC BY-NC 4.0) which permits unrestricted use, distribution, and reproduction in any medium for non-commercial use provided the original author and source are credited.

\section{INTRODUCTION}

MVR indicates a combination of more than three minor moving violations or minor preventable accidents during the past three years. Patients who have each mitral valve dysfunction and atherosclerotic coronary artery disease (CAD) kind a heterogeneous cluster in terms of origin of the control disease, extent of coronary atherosclerosis, left ventricular function, and hemodynamic standing at operation [1]. In recent years, $15 \%$ to $30 \%$ of patients undergoing mitral valve replacement (MVR) or mitral valve repair for nonischemic mitral valve disease have vital CAD [2].
CABG+MVR can be performed safely in patients with moderate-to-severe IMR. CABG+MVR resulted in lower rates of complications than $\mathrm{CABG}$ only. Both surgical approaches resulted in significant improvement of postoperative LVEF. However, there was greater improvement in the CABG+MVR group. Internal thoracic arteries (also called ITA grafts or internal mammary arteries [IMA]) are the most common bypass grafts used. They are the standard of care, and the goal is to use these arteries for every patient who has isolated coronary artery bypass surgery. Heart failure is the most common cause of death among coronary artery bypass 
graft $(\mathrm{CABG})$ patients. Overview. Mitral valve repair and mitral valve replacement are procedures that may be performed to treat diseases of the mitral valve-the valve located between the left heart chambers (left atrium and left ventricle). Several types of mitral valve disease exist. MVR indicates one or more major moving violations or serious preventable accidents within the past three years. Predictors of early mortality related to combined coronary artery bypass attachment (CABG) and mitral valve placement embrace the requirement for replacement versus repair (in some however not all series); however, they will include alternative variables such as age, co-morbid conditions, the urgency of surgery, and left cavity perform [3]. The combination of MVR with open-heart surgery is mostly thought-about to have a bigger early and late mortality than either procedure alone. CAD is often related to bicuspid valve disease, however might not be the explanation for the valve disfunction [4]. Though the incidence of synchronous coronary artery bypass graft with MVR exaggerated considerably from $1988(18 \%)$ to 1997 (28\%), the in-hospital survival rates for a similar 2 periods were similar ( $89 \%$ versus $90 \%$, respectively). Clearly, concomitant $\mathrm{CABG}$ in patients undergoing primary MVR has been shown to be a vital freelance risk issue for short- and long-run mortality [5]. A few studies are out there regarding the result of concurrent CABG and control surgeries among our population. Therefore, we have a tendency to tried to think about early results of synchronous coronary artery bypass graft and MVR and additionally confirm main predictors of mortality among these patients.

\section{Materials ANd MethodS}

This study were preoperative and postoperative clinical characteristics were collected and entered into a database from 175 patients undergoing concurrent CABG with MVR at Department of Cardiac Surgery, Bangabandhu Sheikh Mujib Medical University, Dhaka, Bangladesh from Jun 2018 to July 2020. Information was obtained by clinical and case note review as well as detailed questionnaires to physicians and patients.

\section{Statistical Analysis}

The following variables were collected for statistical analysis including general characteristics, current smoking history (patient regularly smokes a tobacco product/products one or more times per day or has smoked in the 30 days prior to admission) [6], hypercholesterolemia (total cholesterol $\geq 5.0 \mathrm{mmol} / \mathrm{l}$, HDL-cholesterol $\leq 1.0 \mathrm{mmol} / \mathrm{l}$ in men, or $\leq 1.1 \mathrm{mmol} / \mathrm{l}$ in women, triglyceride $\geq 2.0 \mathrm{mmol} / \mathrm{l}$ ) [7], family history of $\mathrm{CAD}$ (first-degree relatives before the age of 55 in men and 65 years in women) [8], hypertension (systolic blood pressure $\geq 140 \mathrm{mmHg}$ and/or diastolic $\geq 90 \mathrm{mmHg}$ and/or on anti-hypertensive treatment) (9), diabetes mellitus (symptoms of diabetes plus plasma glucose concentration $\geq 11.1 \mathrm{mmol} / \mathrm{l}$ or fasting plasma glucose $\geq$ $7.0 \mathrm{mmol} / \mathrm{l}$ or $2-\mathrm{hp} \geq 11.1 \mathrm{mmol} / \mathrm{l}$ ) [10], renal failure (creatinine $>355 \mu \mathrm{mol} / \mathrm{l}$ with a rise of $>44$ units or urine output below $0.3 \mathrm{ml} / \mathrm{kg}$ for $24 \mathrm{~h}$ ), recent myocardial infarction (an acute event with abnormal creatine phosphokinase and troponin levels). Bangladesh Heart Association score, arrhythmia, and left ventricular ejection fraction. We considered four criteria to a complicated postoperative short-term outcome: 1) in-hospital postoperative complications including existence of at least one of these complications: cardiac complications (heart block, cardiac arrest, or atrial fibrillation) and non-cardiac complications (re-intubation, brain stroke, renal failure, or ventilation $\geq 10$ hours); 2) prolonged hospital stay before and after operation; and 3) in-hospital mortality rate (sometimes termed operative mortality) defined as death within 30 days of operation [11].

\section{Data Analysis}

Results were reported as the mean \pm standard deviation (SD) for quantitative variables and percentages for categorical variables. Effects of variables on in-hospital mortality were assessed using Pearson's $\chi^{2}$-test. Predictors exhibiting a statistically significant relation in univariate analysis were taken for multivariate logistic regression analysis to investigate their independence as predictors. Odds ratio (OR) and $95 \%$ confidence intervals $(\mathrm{CI})$ were calculated. $P$ values of 0.05 or less were considered statistically significant. All the statistical analyses were performed using SPSS version 19.0 (SPSS Inc., Chicago, IL, USA) and SAS version 9.1 for Windows (SAS Institute Inc., Cary, NC, USA).

\section{RESULTS}

This study were 175 concurrent CABG with MVR operations performed on patients. The mean age of patients was $57.95 \pm 10.54$ years and $5.7 \%$ were under 40 years. Male/female ratio was 1.05 (male $51.4 \%$, female $48.6 \%$ ). The mean ejection fraction was $48.15 \pm 10.14$ and $\mathrm{BMI} \geq 30$ was $18.3 \%$. The main preoperative patient characteristics are summarized in Table-1. Hypercholesterolemia, hypertension, and congestive heart failure were more common than other variables in concurrent CABG with MVR operation, whereas, infectious endocarditis, and left main disease were less common. In concurrent CABG with MVR operation, NYHA score II, III and IV were found in $46.2 \%, 32.7 \%$, and $11.7 \%$ respectively. Also, mean NYHA score was $2.46 \pm 0.84$. Among all patients, $18.3 \%$ and $2.9 \%$ underwent aortic and tricuspid valve replacement, respectively. Also, $8.6 \%$ of patients underwent tricuspid reconstruction and annuloplasty, whereas, no aortic reconstruction and/or annuloplasty was performed. 


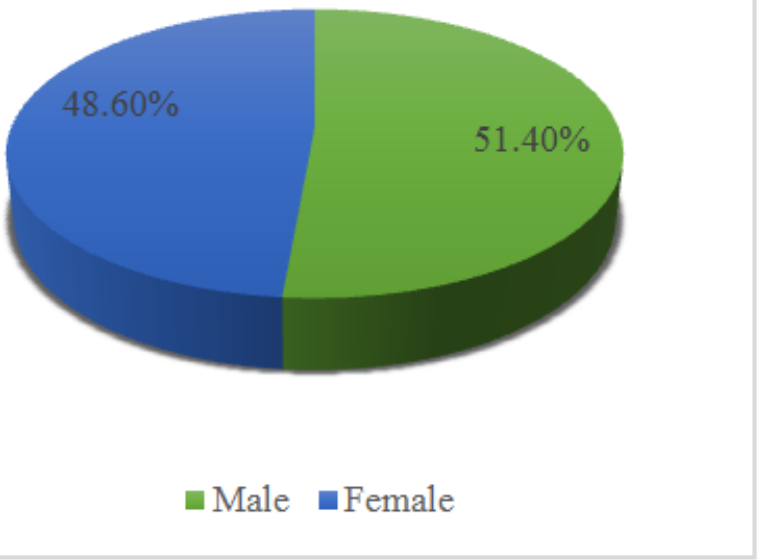

Fig-1: Sex distribution of CABG and MVR patients.

Table-1: The main preoperative patient characteristics of patients underwent concurrent CABG and MVR $(\mathbf{n}=175)$

\begin{tabular}{|c|c|}
\hline Variables & $\%$ \\
\hline Male gender & 51.4 \\
\hline Age $<40$ years & 5.7 \\
\hline $\mathrm{BMI} \geq 30$ & 17.7 \\
\hline Cigarette smoking & 28.2 \\
\hline Family history of $\mathrm{CAD}^{\mathrm{a}}$ & 27.2 \\
\hline Diabetes mellitus & 26.9 \\
\hline Hypercholesterolemia & 54.9 \\
\hline Hypertension & 55.7 \\
\hline Infectious endocarditis & 2.9 \\
\hline Myocardial infarction & 25.1 \\
\hline Congestive heart failure & 56.0 \\
\hline Arrhythmia & 20.7 \\
\hline Ejection fraction $\leq 35 \%$ & 13.7 \\
\hline Left main disease & 9.1 \\
\hline NYHA $^{b}$ score II & 46.2 \\
\hline NYHA score III & 32.7 \\
\hline NYHA score IV & 11.7 \\
\hline Mitral stenosis & 46.3 \\
\hline Mitral insufficiency & 88.9 \\
\hline
\end{tabular}

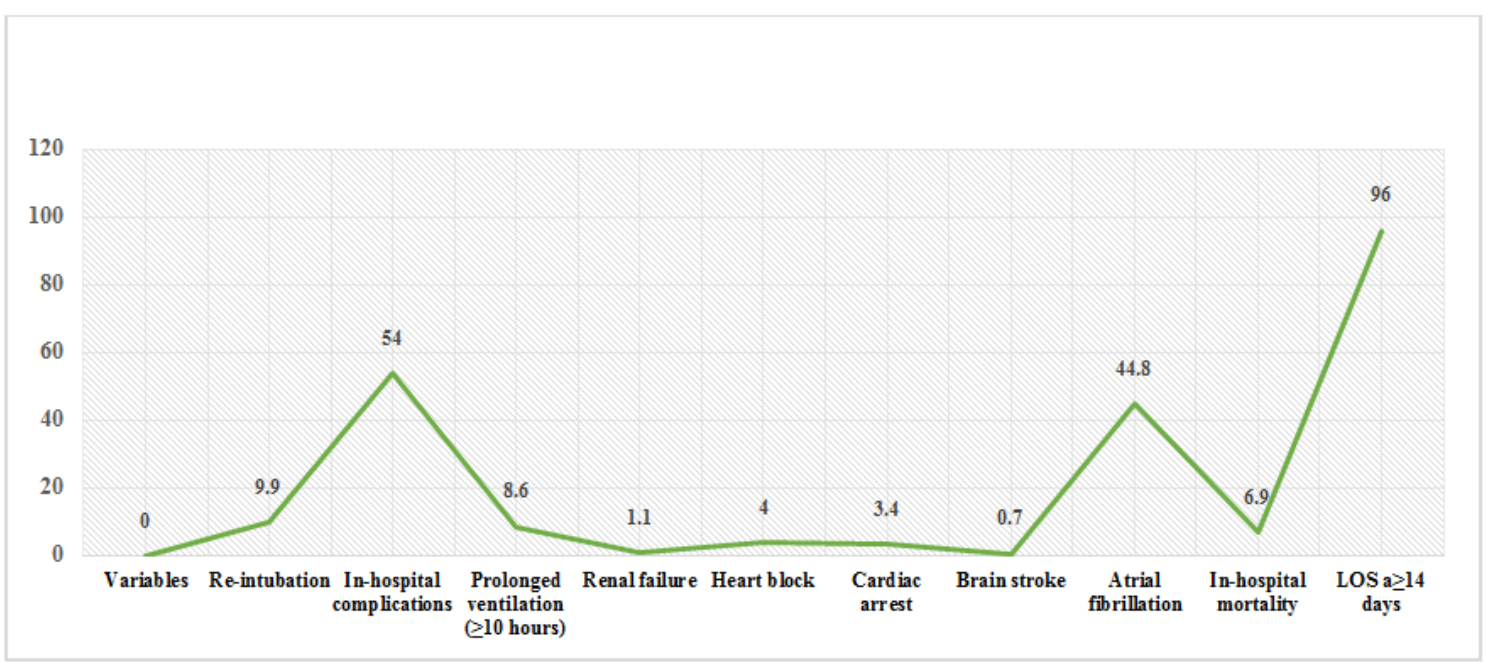

Fig-2: The main postoperative patient characteristics of patients underwent concurrent CABG and MVR 
The main postoperative characteristics are summarized in Figure-2. Among postoperative complications, in-hospital complication and atrial fibrillation were more frequent than other complications. Also, in hospital stay $\geq 14$ days was reported in $96 \%$ of patients. In-hospital mortality in concurrent CABG with MVR was 6.9\%. Multivariate stepwise logistic regression analysis showed that among preoperative characteristics, only history of congestive heart failure (OR: 12.085, 95\% CI: 1.021-143.007, $P=$ $0.027)$ was associated with in-hospital mortality rate. Among postoperative characteristics, postoperative brain stroke (OR: 214.703, 95\% CI: 6.287-415.213, $P$ $=0.004)$ and re-intubation (OR: 159.170, 95\% CI: 16.094-999.99, $P<0.001)$ had a significant relation with in-hospital mortality.

\section{DiSCUSSION}

Increases within

the incidence of serious CAD resulting in MVR combined with CABG features a significant impact on the eventual patient outcome, in order that in-hospital mortality rates for these high risk patients may range from $7 \%$ to $24 \%$ [5]. Various studies have reported the profound effect of CAD on survival after bicuspid valve replacement [1216]. We found that mean NYHA score in patients undergoing concurrent $\mathrm{CABG}$ with MVR operation was 2.46, whereas in Akins et al study, mean score was 3.4 [13]. The impact of etiology of associated mitral disease and a valve procedure on operative and long-term outcomes after coronary bypass surgery grafting surgery is yet to be clearly defined. We also found that mitral stenosis and insufficiency in these patients was $46.3 \%$ and $88.9 \%$, respectively, but these frequencies were $24 \%$ and $76 \%$ in Disesa et al., study [15]. In our study, NYHA score II, III and IV were found in $46.2 \%$, $32.7 \%$, and $11.7 \%$ of patients undergoing concurrent CABG with MVR operation, respectively; whereas these scores were reported elsewhere as $12 \%, 54 \%$, and $29 \%$, respectively [16]. Several studies have shown that severe CAD, acute myocardial infarct, low ejection fraction, ischemic mitral regurgitation, advanced coronary failure symptoms, failure to use internal mammary artery, valve replacement surgery and emergency operations are important predictors of operative mortality $[14,17,18]$. We showed that among preoperative criteria, only congestive heart failure (CHF) was a risk factor for in-hospital mortality of concurrent CABG with MVR operation, whereas age, history of other major predisposing factors for CAD, and NYHA score did not influence on in-hospital mortality. On the other hand, several studies obtained results contrary to ours, reporting high NYHA score as a risk factor for in-hospital mortality in concurrent CABG with MVR operation [14, 19]. However, in isolated MVR operation, NYHA score $\geq 3$ was associated with in-hospital mortality. Similar to our study, in Garcia et al., [19] and Stahle et al., [20] studies, CHF was a major risk factor for in-hospital mortality of concurrent CABG with MVR operation.
The other important result of our study was the role of re-intubation as a risk factor for in-hospital mortality in this type of operation. It seems that mortality caused by re-intubation is more related to complications of reintubation. Patients requiring re-intubation have a poor prognosis, with hospital mortality exceeding 30 to $40 \%$, although the reason remains unclear [21]. Ebstein et al., showed that both cause for extubation failure and time to re-intubation were independently associated with inhospital mortality [21]. In another study, compared with the first intubation and re-intubation, the estimated risk for nosocomial pneumonia has been shown to be 8 times higher and the increase for mortality increased 6to 12-fold [22]. According to Weber's classification, patients in the combined procedure group had mild-tomoderate impairment of aerobic capacity after followup, whereas patients in the CABG surgery only group had moderate-to-severe impairment [23]. Other measures of heart function, including MR volume, plasma B-type natriuretic peptide concentration, and left ventricular end-systolic volume index, also improved to a greater extent in the CABG surgery plus MVR group than in those who underwent CABG surgery only. Survival was $>90 \%$ in both groups at 1 year [23]. MVR is still a reasonable surgical option in many patients with IMR, mainly because of its reliability and reproducibility. It should be considered for patients with acute IMR, and for those with chronic IMR and multiple comorbidities, complex regurgitant jets (noncentral or more than one jet), or severe tethering of both MV leaflets [25-27]. Some studies indicate greater perioperative mortality associated with this procedure, suggesting that preference should be given to less aggressive procedures such as $\mathrm{CABG}$ only or $\mathrm{CABG}$ associated with MVR [24, 25]. However, our study had some limitations. First, although other studies did not show that the incidence of in-hospital mortality of concurrent $\mathrm{CABG}$ with MVR operation was influenced by the operative characteristics, we were not able to determine operative variables and technique effects on complications and outcome. Second, according to the presumably strong relation between re-intubation and in-hospital mortality, other studies are necessary for confirmation of this result.

\section{Conclusion}

In conclusion, based on the outcome of this research, among postoperative characteristics, reintubation and congestive heart failure were associated with in-hospital mortality after concurrent $\mathrm{CABG}$ with MVR operation. Therefore, exact considering and control of these characteristics before and after CABG and MVR are necessary.

Conflict of interests: The authors declare that they have no competing interests.

[Abbreviations: CABG, Coronary Artery Bypass Grafting; CAD, Coronary Artery Disease; MVR, Mitral Valve Regurgitation; LOS, Length of Stay] 


\section{REFERENCES}

1. Lytle BW, Cosgrove DM, Gill CC, Stewart RW, Golding LA, Goormastic M, Taylor PC, Loop FD. Mitral valve replacement combined with myocardial revascularization: early and late results for 300 patients, 1970 to 1983. Circulation. 1985 Jun; 71(6):1179-1190.

2. Enriquez-Sarano M, Klodas E, Garratt KN, Bailey KR, Tajik AJ, Holmes DR Jr. Secular trends in coronary atherosclerosis--analysis in patients with valvular regurgitation. N Engl J Med. 1996 Aug 1; 335(5):316-322.

3. Cohn LH, Rizzo RJ, Adams DH, Couper GS, Sullivan TE, Collins JJ Jr, Aranki SF. The effect of pathophysiology on the surgical treatment of ischemic mitral regurgitation: operative and late risks of repair versus replacement. Eur $\mathbf{J}$ Cardiothorac Surg. 1995; 9(10):568-574.

4. Izhar U, Daly RC, Dearani JA, Orszulak TA, Schaff HV, Mullany CJ. Mitral valve replacement or repair after previous coronary artery bypass grafting. Circulation. 1999 Nov 9; 100(19 Suppl):II84-89.

5. Thourani VH, Weintraub WS, Craver JM, Jones EL, Mahoney EM, Guyton RA. Ten year trends in the treatment of valvular heart disease. Ann Thorac Surg 2000; 70(2):448-55.

6. Barrett-Connor E, Giardina EG, Gitt AK, Gudat U, Steinberg HO, Tschoepe D. Women and heart disease: the role of diabetes and hyperglycemia. Arch Intern Med. 2004 May 10; 164(9):934-942.

7. Wood D, De Backer G, Faergeman O, Graham I, Mancia G, Pyörälä K. Prevention of coronary heart disease in clinical practice: recommendations of the Second Joint Task Force of European and other Societies on Coronary Prevention. Atherosclerosis. 1998 Oct; 140(2):199-270.

8. Bartnik M, Rydén L, Ferrari R, Malmberg K, Pyörälä K, Simoons M, Standl E, Soler-Soler J, Ohrvik J; Euro Heart Survey Investigators. The prevalence of abnormal glucose regulation in patients with coronary artery disease across Europe. The Euro Heart Survey on diabetes and the heart. Eur Heart J. 2004 Nov; 25(21):18801890.

9. 1999 World Health Organization-International Society of Hypertension Guidelines for the Management of Hypertension. Guidelines Subcommittee. J Hypertens. 1999 Feb; 17(2):151183.

10. Kuzuya N. Guidelines for dining out for diabetics. Nippon Rinsho 2002 Oct; 60 Suppl 10:697-705.

11. Edmunds LH Jr, Clark RE, Cohn LH, Grunkemeier GL, Miller DC, Weisel RD. Guidelines for reporting morbidity and mortality after cardiac valvular operations. The American Association for Thoracic Surgery, Ad Hoc Liaison Committee for Standardizing Definitions of Prosthetic Heart Valve Morbidity. Ann Thorac Surg. 1996 Sep; 62(3):932-935.
12. Brandt PW, Partridge JB, Wattie WJ. Coronary arteriography; method of presentation of the arteriogram report and a scoring system. Clin Radiol. 1977 Jul; 28(4):361-365.

13. Akins CW, Buckley MJ, Daggett WM, Hilgenberg $\mathrm{AD}$, Austen WG. Myocardial revascularization with combined aortic and mitral valve replacements. J Thorac Cardiovasc Surg. 1985 Aug; 90(2):272-277.

14. Ashraf SS, Shaukat N, Odom N, Keenan D, Grotte G. Early and late results following combined coronary bypass surgery and mitral valve replacement. Eur J Cardiothorac Surg. 1994; 8(2):57-62.

15. DiSesa VJ, Cohn LH, Collins JJ Jr, Koster JK Jr, VanDevanter S. Determinants of operative survival following combined mitral valve replacement and coronary revascularization. Ann Thorac Surg. 1982 Nov; 34(5):482-489.

16. Szecsi J, Herijgers P, Sergeant P, Daenen W, Scheys I, Flameng W. Mitral valve surgery combined with coronary bypass grafting: multivariate analysis of factors predicting early and late results. J Heart Valve Dis. 1994 May; 3(3):236-242.

17. Chun PK, Gertz E, Davia JE, Cheitlin MD. Coronary atherosclerosis in mitral stenosis. Chest. 1982 Jan; 81(1):36-41.

18. Balu V, Hershowitz S, Zaki Masud AR, Bhayana JN, Dean DC. Mitral regurgitation in coronary artery disease. Chest. 1982 May; 81(5):550-555.

19. Garcia Andrade I, Cartier R, Panisi P, Ennabli K, Grondin CM. Factors influencing early and late survival in patients with combined mitral valve replacement and myocardial revascularization and in those with isolated replacement. Ann Thorac Surg. 1987 Dec; 44(6):607-613.

20. Ståhle E, Bergström R, Malm T, Nyström SO, Hansson HE. Early results of mitral valve replacement. Scand J Thorac Cardiovasc Surg. 1991; 25(3):179-184.

21. Epstein SK, Ciubotaru RL. Independent effects of etiology of failure and time to reintubation on outcome for patients failing extubation. Am J Respir Crit Care Med. 1998 Aug; 158(2):489-493.

22. McLean SE, Jensen LA, Schroeder DG, Gibney NR, Skjodt NM. Improving adherence to a mechanical ventilation weaning protocol for critically ill adults: outcomes after an implementation program. Am J Crit Care. 2006 May; 15(3):299-309.

23. Cully M. Mitral valve repair with CABG surgery. Nat Rev Cardiol, 2013; 10(6). https://doi.org/10.1038/nrcardio.2012.176.

24. Grossi EA, Goldberg JD, LaPietra A, Ye X, Zakow P, Sussman M, Delianides J, Culliford AT, Esposito RA, Ribakove GH, Galloway AC. Ischemic mitral valve reconstruction and replacement: comparison of long-term survival and complications. The Journal of Thoracic and 
Cardiovascular Surgery. 2001 Dec 1;122(6):110724.

25. Gillinov AM, Wierup PN, Blackstone EH, Bishay ES, Cosgrove DM, White J, Lytle BW, McCarthy PM. Is repair preferable to replacement for ischemic mitral regurgitation?. The Journal of thoracic and cardiovascular surgery. 2001 Dec $1 ; 122(6): 1125-41$.
26. Miller DC. Ischemic mitral regurgitation redux to repair or to replace?. J Thorac Cardiovasc Surg, 2000; 122:159-162.

27. Calafiore AM, Di Mauro M, Gallina S, Di Giammarco G, Iacò AL, Teodori G, Tavarozzi I. Mitral valve surgery for chronic ischemic mitral regurgitation. The Annals of thoracic surgery. 2004 Jun 1;77(6):1989-97. 